\title{
The role of the Notch pathway in healthy and osteoarthritic articular cartilage: from experimental models to ex vivo studies
}

\author{
Nadia Sassi¹,2, Lilia Laadhar², Maha Driss ${ }^{3}$, Meriam Kallel-Sellami², Slaheddine Sellami' and Sondes Makni²
}

\begin{abstract}
Osteoarthritis is the most prevalent form of arthritis in the world. With the progressive ageing of the population, it is becoming a major public health problem. The involvement of certain signaling pathways, such as the Notch pathway, during cartilage pathology has been reported. In this review, we report on studies that investigated the expression pattern of the Notch family members in articular cartilage and the eventual involvement of this pathway in the modulation of the physiology and pathology of chondrocytes. Temporal and/or spatial modulation of this signaling pathway may help these cells to synthesize a new functional extracellular matrix and restore the functional properties of the articular cartilage.
\end{abstract}

\section{Introduction}

It is generally believed that once a cell has differentiated its fate is determined and stable. However, several experiments have shown that a differentiated cell, in particular circumstances, can either proliferate to a terminal differentiated state or return to a less differentiated one, a process called dedifferentiation or 'transdifferentiation' [1]. In fact, during dedifferentiation, cells undergo changes at different levels: gene, protein, morphological and functional. This turnover in the cell cycle is probably orchestrated by signaling pathways, the involvement of certain of which during cell dedifferentiation has been reported [2]. Among these pathways, Notch signaling plays a crucial role during cell fate assignment and differentiation/proliferation events. In vertebrates,

*Correspondence: nadiasassitn@yahoo.com

'Osteoarthritis-osteoporosis Research Laboratory, Rheumatology Department,

LaRabta Hospital, 1007 Tunis, Tunisia

Full list of author information is available at the end of the article mutagenesis and misexpression of Notch and its ligands have highlighted numerous roles of this pathway during embryogenesis and the early stages of development [3-5]. Notch signaling has been identified in different developmental systems, especially neurogenesis $[3,4]$ and hematopoeisis [5]. These studies show that Notch signaling, in combination with other cellular factors, influences differentiation, proliferation and apoptosis.

The Notch signaling pathway is highly conserved, from worms to humans. It is considered an important pathway in the development and assignment of cell fates during embryogenesis and the early stages of development as well as in the maintenance of a stem cell population in many tissues throughout life $[6,7]$. Notch receptors are also responsible for the regulation of cell proliferation and differentiation, thus acting as on/off switches that activate either proliferation or differentiation $[6,7]$.

In this review, we focus on studies that investigated the expression pattern of Notch family members from immature to mature articular cartilage and the eventual involvement of the Notch pathway in the modulation of chondrocyte physiology in normal and damaged articular cartilage, particularly in 'osteoarthritic conditions'. Recent studies revealed that Notch is expressed in murine chondrocytes during cartilage development and in chondrocytes from adult normal articular cartilage [8-10]. Therefore, understanding the underlying mechanisms of Notch signaling during these phenotypical changes in chondrocytes occurring during osteoarthritis (OA) may eventually allow scientists to temporally and/ or spatially modulate this signaling pathway in order to help the cells to synthesize a new functional extracellular matrix and restore the functional properties of the articular cartilage.

\section{Historical background of the Notch gene and components of the pathway}

Notch was first discovered in Drosophila melanogaster as a mutant gene. The name 'Notch' derives from the mutations observed on the margins of the Drosophila wings due to Notch mutations. The first 'Notch' mutation 
was found in 1914 by Dexter [11], who showed that the character was sex-linked, dominant in the female Drosophila, and lethal in the male. In 1917, Bridges [12] found a second mutation of this gene, and later several others were found [13]. 'Notch' refers either to the Notch genes, the Notch receptors or the Notch pathway, according to context.

The Notch genes encode Notch receptors. These are $300-\mathrm{kDa}$ transmembrane proteins with a large extracellular domain containing epidermal growth factor repeats essential for the ligand-receptor interaction and a cysteine rich region. The intracellular domain consists of ankyrin repeats, a glutamine-rich domain and a PEST (proline, glutamate, serine, threonine) domain $[14,15]$. The Notch genes differ between species: Drosophila has one, and mammals four, expressing Notch receptors 1, 2, 3 and 4 .

The Notch family also includes genes encoding ligands of the Notch receptors, Delta and Serrate, which are similarly conserved in both invertebrates and vertebrates. Drosophila has only one gene for Serrate and one for Delta, whereas in mammals five genes encode the Notch ligands: Serrate homologues called Jagged1 and 2, and Delta homologues called Delta like 1, 3 and 4. These constitute the DSL (Delta/Serrate/Lag2) family (Figure 1).

\section{Activation of the Notch pathway}

The first described Notch activation cascade consists of a series of cleavages leading to the release of the intracellular domain of the receptor, which interacts in the nucleus with the transcription factor CSL (CBF 1 in humans, Suppressor of hairless in Drosophila, and LAG in Caenorhabditis elegans) to regulate the expression of the target genes [7]. However, recent studies suggest that the CSL-dependent $[16,17]$ signaling pathway does not mediate all functions of Notch [18]. Thus, Notch may act by two distinct processes: CSL-dependent signaling (the canonical pathway) [15] and CSL-independent signaling.

\section{Canonical activation via CSL}

Maturation and activation of the Notch receptor are conserved between species. This process is initiated by cleavage in the trans-Golgi network by a furin convertase. The resulting two fragments are re-associated and proceed to the cell surface as a transmembrane receptor, consisting of an extracellular domain and a Notch tethered membrane. This complex interacts with a neighboring cell expressing the receptor's ligand on its surface and the receptor becomes susceptible to a second cleavage by a metalloprotease from the ADAM (a desintegrin and metalloprotease) family called TACE (tumor necrosis factor alpha converting enzyme). A third cleavage occurs within the transmembrane domain of the receptor and is carried out by $\gamma$-secretase, an enzyme

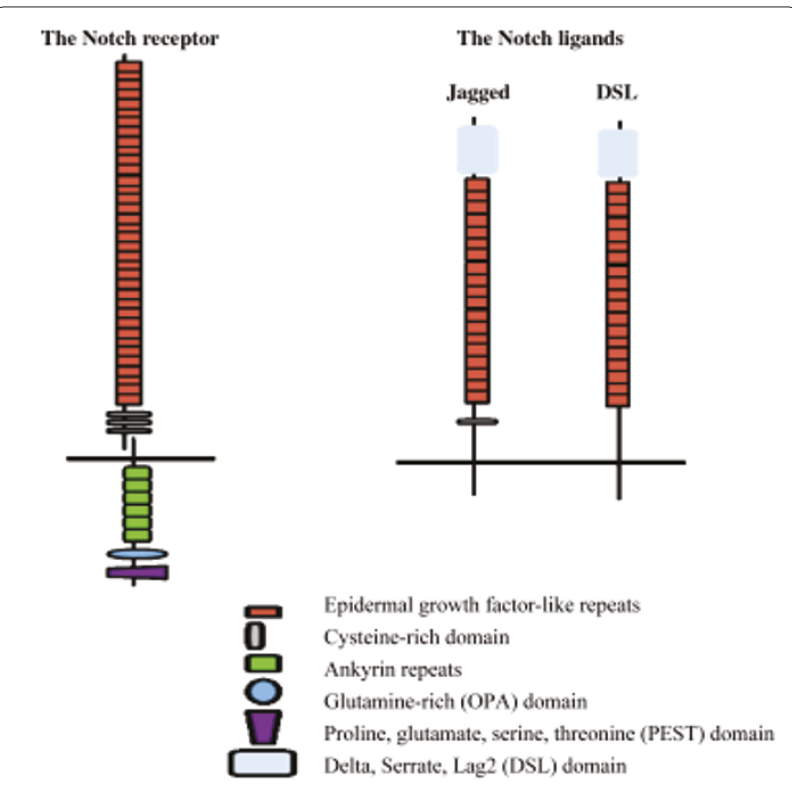

Figure 1. The main components of the Notch receptor and its ligands in mammals.

that generally constitutively cleaves transmembrane proteins with short extracellular stubs. This final cleavage liberates the intracellular domain of the Notch receptor, which translocates to the nucleus and interacts with its downstream transcription factor, CSL, and thereby activates transcription of its target genes [7,18-21] (Figure 2). To date, two major Notch primary target genes have been identified, HES and HERP. These Notch effectors belong to the basic helix-loop-helix family and negatively regulate the expression of downstream target genes in different tissues [22-24].

\section{Non-canonical activation (CSL-independent)}

Several studies have provided evidence for CSLindependent Notch signaling $[25,26]$. Weinmaster and colleagues $[25,26]$ showed that CSL-independent signaling can prevent differentiation of the myogenic cell line C2C12; differentiation was still blocked in cells expressing truncated forms of the Notch intracellular domain, which prevents the activation of the CSL-dependent promoter. These results were confirmed by the co-culture of the $\mathrm{C} 2 \mathrm{C} 12$ cell line with Jagged1-expressing cells. They concluded that Notch signaling can inhibit myogenesis independently of CSL. However, the ligand-induced activation of Notch may lead to signaling through both the CSL-independent and CSL-dependent pathways [26]. In 2008, Maillard and colleagues [27] inhibited the canonical Notch pathway in murine hematopoietic stem cells. The abolishment of the CSL-dependent signal in these cells did not lead to any defect when allowed to compete with normal hematopoietic stem cells in vivo. 


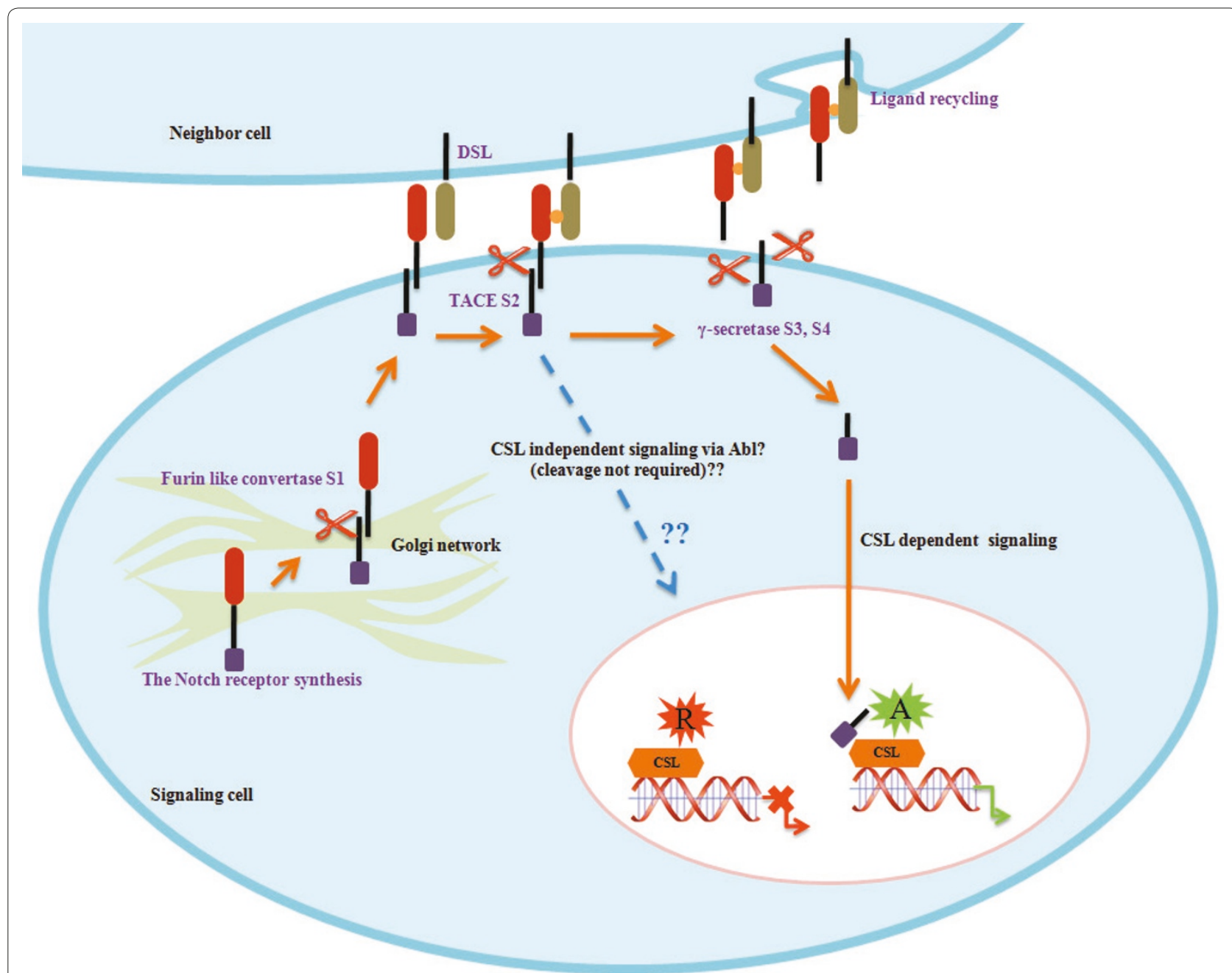

Figure 2. Canonical and non-canonical (Abl) Notch signaling pathways. A, Co-activator; CSL, CBF, Su(H), Lag3; DSL, Delta, Serrate, Lag2; R, co-repressor; S1, S2, S3 and S4, Notch cleavage sites in the canonical signaling pathway; TACE, tumor necrosis factor alpha converting enzyme.

Notch signaling independent of CSL has been reported to occur via Abl (Figure 2). Abl is a cytoplasmic tyrosine kinase that has been widely studied as a protein implicated in cell growth and fate guidance [28-33] and in the etiology of human cancer [34-36]. Interestingly, it has also been reported that mutations affecting Abl signaling result in small decreases in the efficiency of Notch function, affecting cell identity [37]. On the contrary, deletion of the CSL-dependent pathway does not result in deleterious effects on central nervous system longitudinal axon development in Drosophila embryos [38].

The Notch receptor may have differential abilities to trigger canonical and non-canonical signaling, which could eventually lead to reciprocal control of the two signaling pathways $[39,40]$. The two Notch signaling pathways may interact in concert or in a coordinated manner to provide the necessary regulation of nuclear genes encoding cytoskeletal and cell adhesion proteins.

\section{Role of Notch during cartilage development and adulthood}

In vivo, cartilage is formed in mesenchymal cell condensations during the early stages of development. Previous studies showed that Notch family members were expressed in early mesenchymal cell condensations of murine limb rudiments as well as in developing avian cartilage $[9,41]$. It has also been reported that Notch signaling is involved in the maturation of chondrocytes during chick limb development. Crowe and colleagues [42] investigated the expression pattern of Notch family members during chick limb development; they found that neither Notch 1 nor Serrate 1 or 2 were expressed, while Delta 1 and Notch 2 were detected. These authors induced the misexpression of Delta 1 in the presumptive limb region of stage 13 to 16 chick embryos. The results showed that Delta 1 was specifically expressed in hypertrophic chondrocytes during their formation and 
continues to be expressed in these cells. However, the Notch 2 receptor is ubiquitously expressed throughout the limb in all the chondrocytes. Moreover, Delta 1 misexpression prevented prehypertrophic chondrocytes in the chick limb from differentiating into hypertrophic chondrocytes, resulting in a dramatic shortening of the cartilage elements. In this context, the hypertrophic chondrocytes did eventually undergo programmed apoptosis and were replaced by osteoblasts and then osteocytes and finally formed the mature skeleton. In summary, according to these authors progression of chondrocytes from the prehypertrophic state to the hypertrophic state is negatively regulated by Notch/Delta signaling, which also controls the transition of chondrocytes to a terminally differentiated state [42-45]. In addition, Hayes and colleagues [46] showed that Notch receptor 1 was expressed in murine chondrocytes on the surface of articular cartilage before birth and that this expression becomes restricted to deeper layers after birth.

These data suggest that the presence of the Notch receptor is needed for cell differentiation and proliferation before birth in order to form the cartilage elements. During the late stages of development and after birth the expression of the Notch receptor would instead allow the terminal differentiation and maturation of chondrocytes in the deeper layers of cartilage, thus promoting osteochondral ossification. One of the most relevant hypotheses is that Notch may act as an on/off switch, either enabling maturation of the articular cartilage by promoting cell proliferation or acting as a terminal differentiation potential leading to bone formation (and bone elongation after birth).

In order to elucidate the role of Jagged, Oldershaw and colleagues [47] transduced human mesenchymal stem cells (hMSCs) with adenoviral Jagged1. The results of the chondrogenic cell aggregate culture showed a total inhibition of chondrogenesis versus normal chondrogenesis in vector control transduced hMSCs. It has also been shown that long-term Notch/Jagged signaling maintains the progenitor cell state $[47,48]$. Taken together, the results of these studies suggest that Notch/Jagged signaling promotes the maintenance of the progenitor phenotype and even suppresses cell differentiation.

It was also reported that the activation of Notch signaling during development is a matter of timing. Grogan and colleagues [49] showed that the over-expression of the Notch intracellular domain in hMSC pellet culture induced a reduction in type II collagen mRNA levels, suggesting an inhibition of chondrogenesis. However, inhibition of Notch activity by using a $\gamma$-secretase inhibitor (the enzyme responsible for Notch activation) at different stages of chondrogenesis showed that Notch activation and signaling is only necessary during early chondrogenic differentiation. To further elucidate the mechanisms of the Notch repressive response during chondrogenesis, these authors over-expressed the Notch effectors HES-1/HEY-1 in hMSCs. The results showed an alteration in type II collagen and aggrecan expression, thus confirming the essential role played by Notch during chondrocyte differentiation. In 2010, Oldershaw and colleagues [50] showed that inhibiting Notch activation for 14 days in hMSC aggregate culture was only as effective as blocking the pathway during the first 5 days, confirming previous reports by Grogan and colleagues [49]. These results suggest that once Notch has been activated during chondrogenesis, further Notch signaling is not needed [49,50].

Recent studies showed that Notch family members are still expressed in articular cartilage subpopulations even after birth [51,52]. In this context, the continuous development of articular cartilage, as well as the presence of a chondroprogenitor subpopulation and its fate, might be regulated by the Notch pathway. Since chondrocyte differentiation and maturation continue into early stages of development, recent and current studies are more interested in the expression of Notch in post-birth and mature articular cartilage. Indeed, Dowthwaite and colleagues [51] showed that Notch receptor was expressed on the surface of articular cartilage of a 7-dayold calf by a progenitor cell population; this matches previous results in developing mouse articular cartilage [8]. These cells were shown to have increased colony forming efficiency compared with chondrocytes not expressing Notch receptor, suggesting a primordial role for the Notch receptor in controlling the clonality of surface zone chondrocytes [51]. In fact, in both species the Notch receptor is present in the chondrocytes of the surface zone of the articular cartilage. Consistent with these results, Grogan and colleagues showed that over $70 \%$ of chondrocytes on the surface zone of adult human articular cartilage express Notch1 receptor [49,53]. Additionally, Karlsson and colleagues [10] cultured human articular chondrocytes for one passage with and without treatment by a Notch signaling inhibitor; the results showed that blocking Notch activation decreases chondrocyte proliferation compared with controls.

Although these data support the idea that Notch signaling is mainly involved in maintaining clonality and proliferation rather than differentiation, it has not been excluded that this pathway may also promote chondrocyte terminal differentiation [42]. Thus, the precise role of the Notch receptor in promoting proliferation or differentiation after birth remains unclear.

\section{Notch and damaged articular cartilage}

In normal conditions, the chondrocyte is responsible for the synthesis, maintenance and turnover of the 
extracellular matrix of articular cartilage. This matrix is primarily composed of type II collagen and aggrecans [54]. In normal articular cartilage, low turnover of extracellular matrix components is maintained by a balance between anabolic and catabolic factors. In fact, metalloproteinases, especially matrix metalloproteinase (MMP) 13 , are produced by chondrocytes in order to ensure the continuous renewal of collagen fibrils. This production is regulated by the synthesis of tissue inhibitors of MMPs, commonly called TIMPs. During OA, degradation of the extracellular matrix exceeds its synthesis, resulting in a net decrease in the amount of cartilage matrix and even the erosion of joint surfaces [55]. Additionally, chondrocytes undergo phenotypic modifications, including the acquisition of a fibroblast-like morphology, loss of the ability to express collagen II, and increased expression of fetal fibrillar collagen type I, usually known as chondrocyte dedifferentiation. These phenotypical modifications promote matrix degradation and unsuccessful cartilage repair [56,57]. Kouri and Lavalle [1] established a classification scheme for chondrocytes present in OA cartilage based on their ultrastructural characteristics. They identified three types, ranging from normal chondrocytes on non-fibrillated regions to secretory chondrocytes with irregular shape, and apoptotic (chondroptotic) chondrocytes in the deeper fibrillated regions. Thus, they suggested that, following cartilage injury, the chondrocyte is activated and the types of molecules it secretes changes, called the transdifferentiation process. This mechanism is launched in an attempt to repair cartilage, and the failure of this repair results in apoptosis of chondrocytes [1].

In this context, the recently reported expression of Notch family members in adult and even OA cartilage raised the issue of the involvement of this pathway in the physiopathology of OA and especially in the changes that chondrocytes undergo during this process [51,52]. Experimental animal models of OA that have been developed, such as rabbit, rat and dog, have rather focused on the anatomopathology of the disease [58-63]. Thus, scientists have been interested in studying the relationship between morphology and chondrocyte behavior in vitro using monolayer cultures to induce dedifferentiation, although it has been realized that the monolayer expansion of chondrocytes can alter the differentiated phenotype [64]. This was confirmed in a murine model of chondrocyte culture in which cells switched from expressing type II collagen to type I and III collagen starting from day 4 to 8 of culture. The switch in collagen synthesis occurred simultaneously with a loss of the chondrocyte matrix capsule and the emergence of a fibroblast-like morphology [64].

It has been reported that passaged articular chondrocytes in a murine model undergo morphological and structural changes similar to the changes observed in OA chondrocytes, notably a decrease in the expression of type II collagen and an increase in the expression of type I collagen [65]. Some studies have highlighted an eventual involvement of Notch signaling during the dedifferentiation of murine chondrocytes: Blaise and colleagues [66] and our group [67] studied the expression pattern of Notch family members in passaged immature murine articular chondrocytes that had been treated or not with a $\gamma$-secretase inhibitor. The results show that the untreated chondrocytes had decreased expression of type II collagen during the passages but increased MMP13 expression. However, cells treated with the inhibitor during the passages showed a less pronounced decrease in collagen II synthesis and a decrease in MMP13 expression [66]. These authors also showed that transfecting chondrocytes with the active form of the Notch receptor resulted in reduction of MMP13 expression. Moreover, our group showed that the inhibition of this pathway not only slowed the dedifferentiation process, but also inhibited collagen I expression and even led to collagen II re-expression, suggesting eventual chondrocyte redifferentiation [67].

Since Notch signaling is involved not only in differentiation but also in proliferation and apoptosis in developing and mature articular cartilage, recent studies have focused on the involvement of this pathway in joint pathology. Several studies were interested in the interaction between Notch signaling and cartilage subpopulations [68,69]. In 2004, Alsalameh and colleagues [70] showed that normal human articular cartilage may contain a mesenchymal progenitor population, and in 2006, Hiraoka and colleagues [52] linked the expression of the Notch receptor 1 with the presence of a mesenchymal progenitor population.

Consistent with these results, Karlsson and colleagues [71] and Grogan and colleagues [72] showed that the frequency of cells expressing Notch1 is higher in fibrillated OA cartilage compared to healthy cartilage. In the same context, Archer and colleagues [73], in a recent study, isolated and characterized the previously described chondroprogenitor population from human adult articular cartilage. They described this subpopulation as retaining a 'stem cell-like phenotype', and the activation of these cells probably depends on the physiological and pathological parameters surrounding articular chondrocytes.

There is a debate in the literature concerning the origin of this subpopulation. Functional studies were interested in the multilineage potential of these cells. Barbero and colleagues [74] used monolayer expansion of adult human chondrocytes to show that these cells exhibited differentiation plasticity toward chondrocytic, osteoblastic and adipocytic lineages, suggesting that monolayer expansion may induce selection for progenitor cells. This was later 
confirmed by Alsalameh and colleagues [70] using selected chontrocytes from OA patients. Differentiation assays performed by Grogan and colleagues [72] also showed that a subpopulation of chondrocytes representing $0.1 \%$ of the cartilage cells displayed a higher multilineage potential than the rest of the chondrocytes.

Other studies have studied chondrocyte surface markers in order to elucidate the origin of the chondroprogenitor population. Diaz-Romero and colleagues [75] analyzed changes in surface immunologic markers during chondrocyte monolayer expansion and showed that the cell surface marker profile of dedifferentiated chondrocytes has similarities to that previously described for hMSCs. For a better understanding of the origin of dedifferentiating chondrocytes, these authors [76] isolated and cultured human articular chondrocytes and hMSCs and compared their cell surface immunomarker profiles. The results showed that the cartilage cells exhibiting changes in these markers are actually multipotent dedifferentiating chondrocytes rather than a subpopulation of hMSCs proliferating during monolayer expansion. These results are in accordance with the hypothesis reported by De La Fuente and colleagues [77], who showed that dedifferentiated human articular chondrocytes should be considered as a multipotent primitive population.

In summary, whether they are dedifferentiated multipotent chondrocytes or a preexisting hMSC population, these data confirm the eventual involvement of this subpopulation in pathologic cartilage remodeling. Hiraoka and colleagues [52] showed by immunohistochemistry that this chondroprogenitor population in adult human articular cartilage expresses Notch receptors and their ligands Jagged and Delta, which may increase the clonality of these cells. This expression was increased in OA cartilage, which the authors suggested might be due to the large number of chondrocytes in the clusters observed during $\mathrm{OA}$, which are thought to represent cells that hyperproliferated in response to tissue injury [52]. These results suggest that articular cartilage cells (mature chondrocytes and/or mesenchymal progenitor cells) expressing Notch family members may be activated during $\mathrm{OA}$ in order to achieve intrinsic cartilage repair.

\section{Conclusion}

$\mathrm{OA}$ is a multifactorial disease and the degradation of the articular cartilage is a complex process involving several actors, including signaling pathways like the Notch pathway. Further work is required to understand the complexity of Notch signaling during cartilage pathology and chondrocyte dedifferentiation, which is likely to become a new research focus because of its importance in the stem cell field, regenerative medicine and aging biology. Understanding the underlying mechanisms of chondrocyte dedifferentiation is necessary to develop new therapeutic approaches for a better outcome for patients suffering from joint diseases.

\section{Abbreviations \\ hMSC, human mesenchymal stem cell; MMP, matrix metalloproteinase; OA, osteoarthritis.}

\section{Competing interests}

The authors declare that they have no competing interests.

\section{Authors' contributions}

N Sassi: conception and design, collection and assembly of data, drafting of the article, critical revision of the article. L Laadhar: collection and assembly of data, critical revision of the article for important intellectual content, final approval of the article. M Driss: conception and design, critical revision of the article for important intellectual content, final approval of the article. M KallelSellami: conception and design, critical revision of the article for important intellectual content, final approval of the article. S Sellami: conception and design, critical revision of the article for important intellectual content, final approval of the article. S Makni: conception and design, critical revision of the article for important intellectual content, final approval of the article.

\section{Author details}

'Osteoarthritis-osteoporosis Research Laboratory, Rheumatology Department LaRabta Hospital, 1007 Tunis, Tunisia. ${ }^{2}$ mmunology Department, LaRabta Hospital, 1007 Tunis, Tunisia. ${ }^{3}$ Anatomo-pathology Department, Salah Azaiez Health Institute, 1007 Tunis, Tunisia.

Published: 18 March 2011

\section{References}

1. Kouri JB, Lavalle C: Do chondrocytes undergo activation and transdifferentiation during the pathogenesis of osteoarthritis? A review of the ultrastructural and immunohistochemical evidence. Histol Histopathol 2006, 21:793-802.

2. Cai SA, Fu X, Sheng Z: Dedifferentiation: a new approach in stem cell research. Bioscience 2007, 57:655-662.

3. Greenberg DA, Jin K: Turning neurogenesis up a Notch. Nat Med 2006, 12:884-885.

4. Yoon K, Gaiano N: Notch signaling in the mammalian central nervous system: insights from mouse mutants. Nat Neurosci 2005, 8:709-715.

5. Calvi LM, Adams GB, Weibrecht KW, Weber JM, Olson DP, Knight MC, Martin RP, Schipani E, Divieti P, Bringhurst FR, Milner LA, Kronenberg HM, Scadden DT: Osteoblastic cells regulate the haematopoietic stem cell niche. Nature 2003, 425:841-846

6. Tsakonas S A, Matsuno K, Fortini M: Notch signaling. Science 1995, 268:225-232.

7. Tsakonas SA, Rand MD, Lake RJ: Notch signaling: cell fate control and signal integration in development. Science 1999, 284:770-776.

8. Hayes AJ, Dowthwaite GP, Webster SV, Archer CW: The distribution of Notch receptors and their ligands during articular cartilage development. J Anat 2003, 202:495-502

9. Watanabe N, Tezuka Y, Matsuno K, Miyatani S, Morimura N, Yasuda M, Fujimaki R, Kuroda K, Hiraki Y, Hozumi N, Tezuka K: Suppression of differentiation and proliferation of early chondrogenic cells by Notch. J Bone Miner Metab 2003, 21:344-352.

10. Karlsson C, Jonsson M, Asp J: Notch and HES5 are regulated during human cartilage differentiation. Cell Tissue Res 2007, 327:539-551.

11. Dexter JS: The analysis of a case of continuous variation in Drosophila by a study of its linkage relations. Am Nat 1914, 48:712-758.

12. Bridges CB: Deficiency. Genetics 1917, 2:445-465.

13. Morgan LV: Non-criss-cross inheritance in Drosophila melanogaster. Biol Bull 1922, 42:267-274.

14. Brou C: intracellular trafficking of Notch receptors and ligands. Exp Cell Res 2009, 315:1549-1555

15. Talora C, Campese AF, Bellavia D, Felli MP, Vacca A, Gulino A, Screpenti I: Notch signaling and diseases: an evolutionary journey from a simple beginning to complex outcomes. Biochem Biophys Acta 2008, 1782:489-497. 
16. Egan S E, Pierre B, Leow C: Notch receptors, partners and regulators: from conserved domains to powerful functions. Curr Top Microbiol Immunol 1998, 228:273-324.

17. Kao HY, Ordentlich P, Koyano Nakagawa N, Tang Z, Downes M, Kintner CR, Evans RM, Kadesch T: A histone desacetylase corepressor complex regulates the Notch signal transduction pathway. Genes Dev 1998, 12:2269-2277.

18. Arias AM, Zecchini V, Brennan K: CSL-independant Notch signaling: a checkpoint in cell fate decisions during development? Curr Opin Gene Dev 2002, 12:524-533.

19. Fortini M: Notch and presenilin: a proteolytic mechanism emerges. Curr Opin Cell Biol 2001, 13:627-634.

20. Schweisguth F: Regulation of Notch signaling activity. Curr Biol 2004, 14:129-138.

21. Fiùza UM, Arias AM: Cell and molecular biology of Notch. J Endocrino/ 2007, 194:459-474.

22. Ohsako S, Hyer J, Panganiban G, Oliver I, Caudy M: Hairy function as a DNAbinding helix-loop-helix repressor of Drosophila sensory organ formation. Genes Dev 1994, 8:2743-2755.

23. Ohtsuka T, Ishibashi M, Gradwohl G, Nakanishi S, Guillemot F, Kageyama R: Hes 1 and Hes5 as notch effectors in mammalian neuronal differentiation. EMBO / 1999, 18:2196-21207.

24. Iso T, Kedes L, Hamamori Y: HES and HERP families: multiple effectors of the Notch signaling pathway. J Cell Physiol 2003, 194:237-255.

25. Shawber C, Nofziger D, Hsieh JD, Lindsell C, Bögler O, Hayward D, Weinmaster G: Notch signaling inhibits muscle cell differentiation through a CBF1independent pathway. Development 1996, 122:3765-3773.

26. Donna Nofziger D, Alison Miyamoto A, Karen M, LyonsKM, Weinmaster G: Notch signaling imposes two distinct blocks in the differentiation of C2C12 myoblasts. Development 1999, 126:1689-1702.

27. Maillard I, Koch U, Dumortier A, Shestova O, Xu L, Sai H, Pross SE, Aster JC, Bhandoola A, Radtke F, Pear WS: Canonical Notch signaling is dispensable for the maintenance of adult hematopoietic stem cells. Stem Cell 2008, 2:356-366.

28. Baum B, Perrimon N: Spatial control of the actin cytoskeleton in Drosophila epithelial cells. Nat Cell Biol 2001, 3:883-890.

29. Bear JE, Loureiro JJ, Libova I, Fassler R, Wehland J, Gertler FB: Negative regulation of fibroblast motility by Ena/VASP proteins. Cell 2000, 101:717-728.

30. Gertler FB, Bennett RL, Clark MJ, Hoffmann FM: Drosophila Abl tyrosine kinase in embryonic CNS axons: A role in axonogenesis is revealed through dosage-sensitive interactions with disabled. Cell 1989, 58:103-113.

31. Grevengoed EE, Loureiro JJ, Jesse TL, Peifer M: Abelson kinase regulates epithelial morphogenesis in Drosophila. J Cell Biol 2001, 155:1185-1198.

32. Luo L: Trio quartet in D. melanogaster. Neuron 2000, 26:1-2.

33. Wills Z, Bateman J, Korey CA, Comer A, Van Vactor D: The tyrosine kinase Abl and its substrate enabled collaborate with the receptor phosphatase Dlar to control motor axon guidance. Neuron 1999, 22:301-312.

34. Druker BJ, Talpaz M, Resta DJ, Peng B, Buchdunger E, Ford JM, Lydon NB, Kantarjian H, Capdeville R, Ohno-Jones S, Sawyers CL: Efficacy and safety of a specific inhibitor of the BCR-ABL tyrosine kinase in chronic myeloid leukemia. N Engl J Med 2001, 344:1031-1037.

35. Fainstein E, Marcelle C, Rosner A, Canaani E, Gale RP, Dreazen O, Smith SD, Croce CM: A new fused transcript in Philadelphia chromosome positive acute lymphocytic leukemia. Nature 1987, 330:386-388.

36. Goff SP, Gilboa E, Witte ON, Baltimore D: Structure of the Abelson murine leukemia virus genome and the homologous cellular gene: Studies with cloned viral DNA. Cell 1980, 22:777-785.

37. Giniger E: A role for Abl in Notch signaling. Neuron 1998, 20:667-681

38. Le Gall M, De Matter C, Giniger E: Molecular separation of two signaling pathways for the receptor Notch. Dev Biol 2008, 313:556-567.

39. Espinosa L, Ingles-Esteve J, Robert-Moreno A, Bigas A: IkappaBalpha and p65 regulate the cytoplasmic shuttling of nuclear corepressor: crosstalk between Notch and NFkappaB pathways. Mol Biol Cell 2003, 14:491-502

40. Vacca A Felli M.P, Palermo R, Di Mario G, Calce A, Di Giovine M, Frati L, Gulino A, Screpanti I: Notch3 and pre-TCR interaction unveils distinct NF-kappaB pathways in T-cell development and leukemia. EMBO J 2006, 25:1000-1008.

41. Williams R, Nelson L, Dowthwaite GP, Evans DJ, Archer CW: Notch receptor and Notch ligands expression in developing avian cartilage. J Anat 2009, 215:159-169.

42. Crowe R, Zikherman J, Niswander L: Delta 1 negatively regulates the transition from prehypertrophic chondrocytes to hypertrophic chondrocytes. Development 1999, 126:987-998.

43. Bolos V, Grego-Bessa J, de la Pompa JL: Notch signaling in development and cancer. Endocr Rev 2007, 28:339-369.

44. Henson FM, Bowe EA, Daves ME: Promotion of the intrinsic damage-repair response in articular cartilage by fibroblast growth factor. Osteoarth Cartil 2005, 13:537-544

45. Hardingham TE, Oldershaw R, Tew RS: Cartilage, sox9 and Notch signals in chondrogenesis. J Anat 2006, 209:469-480

46. Hayes AJ, MacPherson S, Morrisson H, Dowthwaite GP, Archer CW: The development of articular cartilage evidence of an appositional growth mechanism. Anat Embryol 2001, 203:469-479.

47. Oldershaw R, Murdoch A, Brennan K: The putative role of the Notch ligand, jagged 1 , in the mediation of the early events of human mesenchymal stem cell chondrogenesis. Int J Exp Pathol 2005, 86:47-48.

48. Kageyama R, Ohtsuka T, Hatakeyama J, Ohsawa R: Roles of bHLH genes in neural stem cell differentiation. Exp Cell Res 2005, 306:343-348.

49. Grogan SP, Tsaiwei Olee T, Hiraoka K, Lotz MK: Notch signaling proteins Hes-1 and Hey-1 bind N-box domains in the Col2a1 enhancer site to repress chondrogenesis. Arthritis Rheum 2008, 58:2754-2763.

50. Oldershaw R, Hardingham TE: Notch signaling during chondrogenesis of human bone marrow stem cells. Bone 2010, 46:286-293.

51. Dowthwaite G, Bishop J, Redman S, Khan IM, Rooney P, Evans DJR, Haughton L, Bayram Z, Boyer S, Thomson B, Wolfe MS, Archer CW: The surface of articular cartilage contains a progenitor cell population. J Cell Sci 2004 117:889-897.

52. Ustunel I, Ozenci AM, Sahin Z, Ozbey O, Acar N, Tanriover G, Celik-Ozenci C, Demir R: The immunohistochemical localization of Notch receptors and ligands in human articular cartilage, chondroprogenitor culture and ultrustructural characterestics of these progenitor cells. Acta Histochem 2008, 110:397-407.

53. Grogan SP, Miyaki S, Asahara H, D'Lima D, Lotz MK: Mesenchymal progenitor cell markers in human articular cartilage: normal distribution and changes in osteoarthritis. Arthritis Res Ther 2009, 11:R85.

54. Laadhar L, Zitouni M, Kallel-Sellami M, Mahjoub M, Sellami S, Makni S: Physiopathology of osteoarthritis: from normal cartilage to osteoarthritic cartilage: risk factors and inflammatory mechanisms. Rev Med Int 2007, 28:531-536.

55. Nagase H, Kashiwagi M: Aggrecanases and cartilage matrix degradation. Arthritis Res 2003, 5:94-103.

56. Poole A R, Kobayashi M, Yasuda T, Laverty S, Mwale F, Kojima T, Sakai T, Wahl C, El-Madawy S, Webb G, Tchetina E, Wu W: Type II collagen degradation and its regulation in articular cartilage in osteoarthritis. Ann Rheum Dis 2002, 61:78-81.

57. Van Beuningen HM, stoop R, Buma P, Takahashi N, Van Der Kraan PM, Van Den Berg WB: Phenotypic differences in murine chondrocyte cell lines from mature articular cartilage. Osteoarth Cartil 2002, 10:977-986.

58. Eyre DR, McDevitt CA, Billigham MEG, Muir H: Biosynthesis of collagen and other matrix proteins by articular cartilage in experimental osteoarthritis. Biochem J 1998, 188:823-837.

59. Burton-Wuster N, Hui-Chou CS, Greisen HA, Lust G: Reduced deposition of in the degenerated articular cartilage of dogs with degenerative joint disease. Biochem Biophys Acta 1982, 718:74-84.

60. Miller DR, Lust G: Accumulation of procollagen in the degenerative articular cartilage of dogs with osteoarthritis. Biochem Biophys Acta 1979, 583:218-231.

61. Abbud Lozoya K, Kouri JB: A novel rat osteoarthritis model to assess apoptosis and matrix degradation. Pathol Res Pract 2000, 196:729-745.

62. Kouri Flores JB, Abbud Lozoya K, Morales RL: Kinetics of the ultrastructural changes in apoptotic chondrocytes from an osteoarthritic rat model: a window of comparison to the cellular mechanisms of apoptosis in human chondrocytes. Ultrastructur Pathol 2002, 26:33-40.

63. Matyas JR, Huang D, Chung M, Adams ME: Regional quantification of cartilage type II collagen and aggrecan messenger RNA in joints with early experimental osteoarthritis. Arthritis Rheum 2002, 46:1536-1543.

64. Grundmann K, Zimmermann B, Barrach HJ, Merker HJ: Behaviour of epiphyseal mouse chondrocyte populations in monolayer culture: Morphological and immunohistochemical studies. Virchows Arch A Pathol Anat Histol 1980, 389:167-187

65. Salvat C, Pigenet A, Humbert L, Berembaum F, Thirion S: Immature murine articular chondrocytes in primary culture: a new tool for investigating 
cartilage. Osteoarth Cartil 2005, 13:243-249.

66. Blaise R, Mahjoub M, Salvat C, Barbe U, Brou C, Corvol MT, Savouret JF, Rannou F, Berenbaum F, Bausero P: Involvement of the Notch pathway in the regulation of matrix metalloproteinase 13 and the de-differentiation of articular chondrocytes in murine cartilage. Arthritis Rheum 2009, 60:428-439.

67. Sassi N, Laadhar L, Mahjoub M, Kallel-Sellami M, Zitouni M, Makni S, Sellami S: Expression of Notch family members in cultured murine articular chondrocytes. Biotech Histochem 2009, 84:313-320.

68. SvanvikT, Barreto Henriksson H, Karlsson C, Hagman M, Lindahl A, Brisby H: Human disk cells from degenerated disks and mesenchymal stem cells in co-culture result in increased matrix production. Cells Tissues Organs 2010, 191:2-11.

69. Dong Y, Jesse AM, Kohn A, Gunnell LM, Honjo T, Zuscik MJ, O'Keefe RJ, Hilton MJ: RBPjk-dependent Notch signaling regulates mesenchymal progenitor cell proliferation and differentiation during skeletal development. Development 2010, 137:1461-1471.

70. Alsalameh S, Amin R, Gemba T, Lotz M: Identification of mesenchymal progenitor cells in normal and osteoarthritic human articular cartilage. Arthritis Rheum 2004, 50:1522-1532.

71. Hiraoka K, Grogan S, Olee T, Lotz M: Mesenchymal progenitor cells in adult human articular cartilage. Biorheology 2006, 43:447-454.

72. Karlsson C, Brantsing C, Egell S, Lindahl A: Notch1, Jagged1, and HES5 are abundantly expressed in osteoarthritis. Cells Tissues Organs 2008, 188:287-298.

73. Williams R, llyas M, Khan IK, Kirsty Richardson K, Larissa Nelson L, McCarthy H, Analbelsi T, Singhrao SK, Dowthwaite GP, Jones RE, Baird DM, Lewis H, Roberts
S, Shaw HM, Dudhia J, Fairclough J, Briggs T, Archer CW: Identification and clonal characterisation of a progenitor cell sub-population in normal human articular cartilage. PLOS ONE 2010, 5:e13246.

74. Barbero A, Ploegert S, Herherer M, Martin I: Plasticity of clonal populations of dedifferentiated adult human articular chondrocytes. Arthritis Rheum 2003, 48:1315-1325.

75. Diaz-Romero J, Gaillard JP, Grogan SP, Nesic D, Trub T, Mainil-Varlet P: Immunophenotypic analysis of human articular chondrocytes: changes in surface markers associated with cell expansion in monolayer culture. J Cell Physiol 2005, 202:731-742.

76. Diaz-Romero J, Nesic D, Grogan SP, Heini P, Mainil-Varlet P: Immunophenotypic changes of human articular chondrocytes during monolayer culture reflect bona fide dedifferentiation rather than amplification of progenitor cells. J Cell Physiol 2008, 214:75-83.

77. De la Fuente R, Abad JL, Castro JG, Miguel GF, Petriz J, Rubio D, Abejon CV, Guillen P, Gonzalez MA, Bernada A: Dedifferentiated adult articular chondrocytes: a population of human multipotent primitive cells. Exp Cell Res 2004, 297:313-328.

doi:10.1186/ar3255

Cite this article as: Sassi $\mathrm{N}$, et al:: The role of the Notch pathway in healthy and osteoarthritic articular cartilage: from experimental models to ex vivo studies. Arthritis Research \& Therapy 2011, 13:208. 